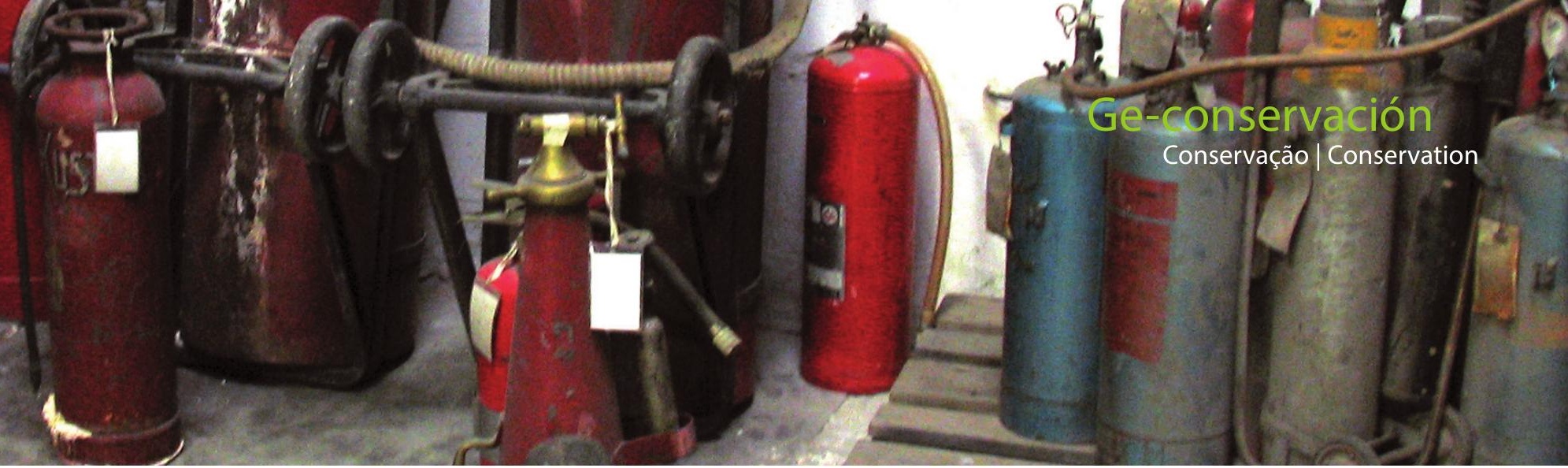

\title{
Diagnóstico del estado de conservación de colecciones científico-técnicas: extintores históricos del MUNCYT
}

\author{
Andrea Díaz-Cortés, Blanca Ramírez Barat, Joaquina Leal, Irene Llorente, Marian del Egido y \\ Emilio Cano
}

\begin{abstract}
Resumen: La correcta identificación de los materiales que conforman los bienes muebles del patrimonio científico-técnico y de las interacciones entre los mismos es necesaria para establecer estrategias de conservación eficaces con criterios de intervención adaptados. En este trabajo se presenta un estudio del estado de conservación, materiales y patologías de la colección de extintores del Museo Nacional de Ciencia y Tecnología. Se ha realizado una base de datos con 56 extintores, documentando cada pieza, tipología y estado de conservación. Los análisis realizados en varias de ellas (por fluorescencia de rayos $\mathrm{X}$ y difracción de rayos $\mathrm{X}$ ) han permitido identificar los materiales de los extintores, en algunos casos del contenido de los mismos, y establecer causas de degradación. En el caso de los extintores de espuma y de agua, se ha mostrado que el agente extintor es altamente corrosivo y ha causado daños severos a la pieza. En estos casos, resulta aconsejable eliminar el contenido si se quiere asegurar una correcta conservación de los extintores.
\end{abstract}

Palabras clave: colecciones científico-técnicas, conservación, extintores, corrosión, DRX, FRX

\section{Diagnosis of the condition of scientific and technical collections: historical extinguishers of the MUNCYT}

\begin{abstract}
The correct identification of the materials of assets that make up the movable scientific and technical heritage and the interactions between them is essential to establish effective conservation strategies with adapted intervention criteria. In this work, a study of the conservation condition, materials and pathologies of the collection of fire extinguishers of the National Museum of Science and Technology is presented. A database has been created with 56 fire extinguishers from the museum, documenting each object, typology and conservation condition. The analyses carried out on some of them (by X-ray fluorescence and X-ray diffraction) have made it possible to identify the materials of the fire extinguishers, in some cases their contents, and to establish degradation mechanisms. In the case of foam and water fire extinguishers, it has been shown that the extinguishing agent is highly corrosive and has caused severe damage to the objetct. In these cases, it is advisable to eliminate the content if correct conservation of the fire extinguishers is to be ensured.
\end{abstract}

Keyword: scientific-technical collection, conservation, fire extinguisher, corrosion, XRD, XRF

\section{Diagnóstico do estado de conservação de coleções científico-técnicas: extintores históricos do MUNCYT}

Resumo: A correta identificação dos materiais que constituem os bens móveis do património científico-técnico e das interações entre eles é necessária para estabelecer estratégias de conservação eficazes com critérios de intervenção adequados. Este trabalho apresenta um estudo sobre o estado de conservação, materiais e patologias do acervo de extintores do Museu Nacional de Ciência e Tecnologia. Foi feita uma base de dados com 56 extintores, documentando cada peça, tipo e estado de conservação. As análises realizadas em vários deles (por fluorescência de raios $X$ e difração de raios X) permitiram identificar os materiais dos extintores, em alguns casos o seu conteúdo, e estabelecer as causas da degradação. No caso de extintores de espuma e água, o agente extintor mostrou ser altamente corrosivo e causou graves danos à peça. Nestes casos, é aconselhável remover o conteúdo se se desejar garantir a preservação adequada dos extintores. 


\section{Introducción}

Las colecciones científico-técnicas tienen un importante papel en la construcción de la memoria científica de nuestras sociedades y en el desarrollo de una cultura (Pacheco Muñoz 2007). A pesar del reconocimiento de que este tipo de objetos forman parte también de nuestra historia y nuestra cultura, y nos informan acerca del estado de la ciencia y la tecnología en su época y su papel en la vida cotidiana del momento, la valoración del patrimonio científico-técnico en nuestro país no se reconoce ni cultural ni socialmente a los niveles del patrimonio artístico o arqueológico.

Al igual que otros tipos de patrimonio, las colecciones científico-técnicas reúnen objetos que forman parte de nuestro legado cultural y deben ser preservadas para generaciones futuras. Sin embargo, la conservación de colecciones supone un reto importante y específico de este tipo de patrimonio, desde varios puntos de vista.

Una de las principales características de estos objetos es su uso a lo largo del tiempo (Gual Via 2015). Son objetos creados para ser utilizados en el día a día de la sociedad: investigación, enseñanza, industria, economia, ambito doméstico etc. Esto provoca, además de su deterioro material, su pérdida completa, ya que no suelen identificarse como parte de un patrimonio interesante para conservar, sino como un objeto útil que cuando termina su periodo de funcionamiento -bien porque existen modelos nuevos, más precisos o con más utilidades en el mercadose desecha.

Este problema se refleja también a la hora de establecer un plan de conservación adecuado en estas colecciones. $\mathrm{Si}$ bien, existen algunos documentos de referencia sobre el Patrimonio Industrial como la Carta Nizhny Tagil 2003 (TICCIH y ICOMOS 2003) y el Plan Nacional de Conservación del Patrimonio Industrial (2015), la mayor parte de las cuestiones que se abordan son muy globales y en la práctica están más orientadas hacia el patrimonio inmueble, mientras que el problema de la conservación del patrimonio mueble en las colecciones científico-técnicas presenta características particulares que requieren un abordaje específico (Wain 2017).

De manera general, la conservación en los museos de ciencia y tecnología demanda la monitorización de factores similares a las de otras colecciones patrimoniales. Sin embargo, existen ciertas características que hacen a este patrimonio más vulnerable frente a determinados riesgos. Por un lado está la coexistencia y diversidad de materiales en los objetos, que dificulta la conservación por motivos de diferentes necesidades de cada material o por problemas de compatibilidad - algo que no es exclusivo de este tipo de colecciones-. Pero además, en ocasiones podemos encontrarnos con objetos que contienen sustancias tóxicas o peligrosas, que incluso están prohibidas por razones de seguridad y salud en la actualidad (Leal Pérez Chao 2016).
Profesionales de la conservación deben enfrentarse a estas problemáticas y establecer criterios partículares para estos objetos, lo que no resulta una tarea sencilla, tendiéndose a conservar el objeto inactivo y perdiendo, de alguna manera, valor documental como objeto útil (Ball 2009; Henderson y Waller 2016).

El problema de la conservación de este tipo de colecciones ha despertado interés en los últimos años dando lugar a un número creciente de publicaciones sobre la definición y exposición de criterios de preservación de estos objetos (Hallam 2007; Ashton y Hallam 1990; Thurrowgood y Hallam 2004; Beet y Coulls 2010; Brunott et al. 2010; Gual Via 2015; Mitchell 2015). También recientemente se han desarrollado algunos proyectos que abordan en especial el problema de los materiales metálicos, que representan una elevada proporción dentro de la diversidad de materiales que componen el patrimonio científico-técnico (Gual Via 2015; Martín et al. 2015; Michel y Brambilla 2016). En esta línea, presentamos un estudio del estado de conservación de la colección de extintores del Museo Nacional de Ciencia y Tecnologia de España (MUNCYT).

\section{- Historia de los extintores}

De todos es conocido el intenso trabajo científico desarrollado a lo largo de su vida por el físico y químico irlandés Robert Boyle (1627-1691). Su influyente libro, El químico escéptico, apareció traducido al español 350 años después de su primera publicación, por iniciativa del Museo Nacional de Ciencia y Tecnología. Boyle, defensor del método experimental, abrió el camino a la química científica superando los métodos de la alquimia, aunque conservando algunos de los retos que le eran propios como el secreto de la transmutación, "piedra filosofal" que transformaría los metales en oro. En el camino de esa búsqueda se encontró con el fósforo gracias a la habilidad de uno de sus ayudantes, Ambrose Godfrey Hanckwitz (1660-1741). Godfrey, de origen alemán, se trasladó a Londres a trabajar con Robert Boyle. Fue en su laboratorio donde impulsó unos estudios experimentales que le llevaron a adquirir, con el apoyo de su maestro, prestigio y fortuna como el mejor fabricante de fósforos. Godfrey es también el inventor del primer extintor, que patentó en 1723, constituido por un reservorio con una solución liquida conectada a un recipiente de estaño con pólvora, que al hacerla explotar, propagaba el líquido de extinción (MacLeod 1998).

La versión moderna del extintor no llegó hasta muchos años después, de la mano de William George Manby (1775-1854). Militar y miembro de la Royal Society, Manby patentó en el año 1813 un extintor portátil que consistía en cuatro cilindros metálicos, uno de aire comprimido y tres llenos de agua a la mitad. En la parte superior contaba con una válvula que, al ser accionada, liberaba el agua a presión a través de una manguera. En este mecanismo se basan los extintores modernos, perfeccionándose con el tiempo y sustituyendo el agua por otras sustancias. 
El médico francés François Carlier, en el año 1866, patentó una combinación diferente. Introdujo el uso del bicarbonato sódico y ácido tartárico, cuya mezcla producía anhídrido carbónico, gas que impulsaba el agua a presión al exterior (Hall 2000). Estos sistemas, sin embargo, no funcionaban ante fuegos provocados por líquidos inflamables como aceites y pinturas. En 1905 Alexander Laurent, utilizó la espuma producto de la mezcla de sulfato de aluminio y bicarbonato sódico con un agente estabilizador. Las burbujas de la espuma eran de anhídrido carbónico y flotaban sobre la superficie del líquido inflamado sustituyendo al oxígeno y con ello, eliminando la posibilidad de combustión (Hall 2000). Este tipo de extintores se generalizó hasta mediados de siglo.

En 1910 el neoyorquino Edward M. Davidson (1911) firmó una patente de un procedimiento de extinción de incendios basado en el uso de tetracloruro de carbono, compuesto químico sintético. Este gas era expulsado hacia el exterior por anhídrido carbónico a presión. En contacto con el oxígeno del aire formaba un gas pesado incombustible que apagaba el fuego de manera fulminante. El objetivo inicial era la extinción de los fuegos en sistemas e instalaciones eléctricas. Este sistema fue eliminado en la década de 1960 por su elevada toxicidad.

A partir de 1950 la empresa Dupont desarrolló un sistema basado en el uso del halón como agente extintor. Los halones son agentes extintores que han jugado un papel muy relevante en la protección de incendios en la segunda mitad del siglo XX, hasta su prohibición según el convenio internacional al que se conoce como Protocolo de Montreal, cuya consecuencia fue el cese de su fabricación en 1994, y la orden de ser retirados para su destrucción o reciclado para antes del 31 de Diciembre de 2003.

A partir de 1950 se empezaron a comercializar extintores cargados con polvo químico formado por bicarbonato sódico tratado accionado por un botellón de presión auxiliar de $\mathrm{CO}_{2}$. A medida que se acrecentó el empleo de líquidos inflamables, aparecieron agentes en polvos más efectivos. En 1959 se introdujo el de bicarbonato potásico dos veces más eficaz que el de bicarbonato sódico ordinario. Se conseguía, de este modo, un equipo de tamaño más reducido y polivalente. Este nuevo extintor vino a Europa con el modelo Super-K que se inventó a principios de los años 60 .

Se han mencionado brevemente los hitos más significativos en la evolución de estos aparatos, que han reunido el avance de la química con el de la protección activa contra incendios, y cuyo testimonio material representa la colección de extintores históricos del MUNCYT. La versión moderna de los extintores se utiliza desde mediados del siglo XX con variantes significativas fruto de la mejora en el uso de compuestos químicos para la extinción que se han ido inventando a lo largo de estos años, de su adaptación a normativas de seguridad y salud y de respeto al medio ambiente.

\section{—La colección de extintores históricos del MUNCYT}

El conjunto estudiado en este trabajo se compone de un total de 56 objetos ubicados en el almacén del museo situado en el Paseo de las Delicias de Madrid. Estos se dividen en dos grupos de acuerdo con su periodo de fabricación e interes patrimonial.

El primer grupo lo conforman 34 extintores, los más antiguos, fabricados desde principios del siglo XX hasta la década de los 70. De ellos, 14 poseen un número de inventario, fomando parte de la colección histórica; y los 20 restantes todavía no se encuentran inventariados (estando 10 de ellos pendientes de su incorporación a la colección). Los 3 más antiguos de la colección [Figura 1] se conservan en los armarios compactos y el resto en el almacén paletizado [Figura 2].

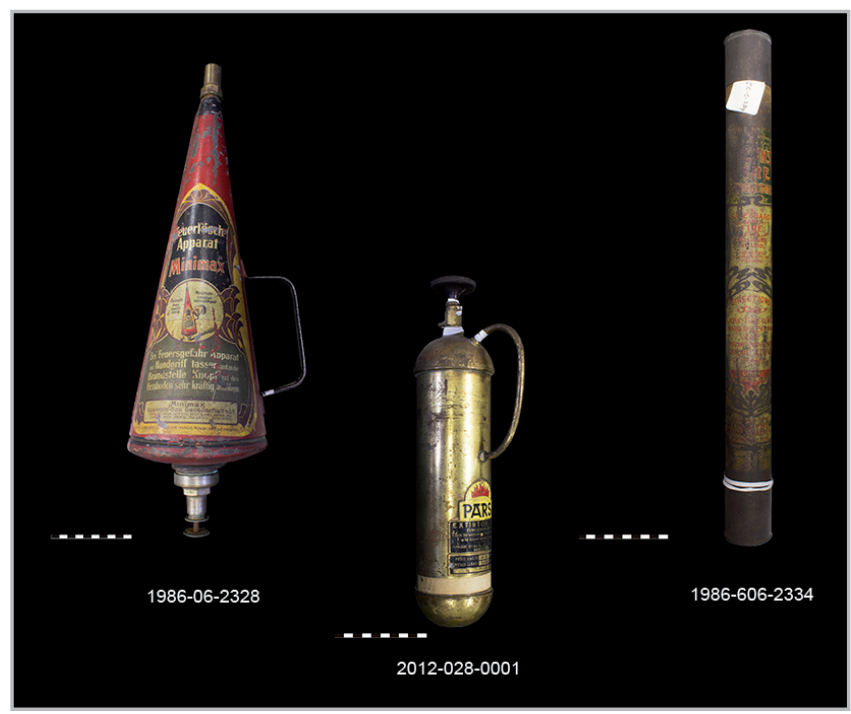

Figura 1.- Extintores preservados en los almacenes compactos del MUNCYT.

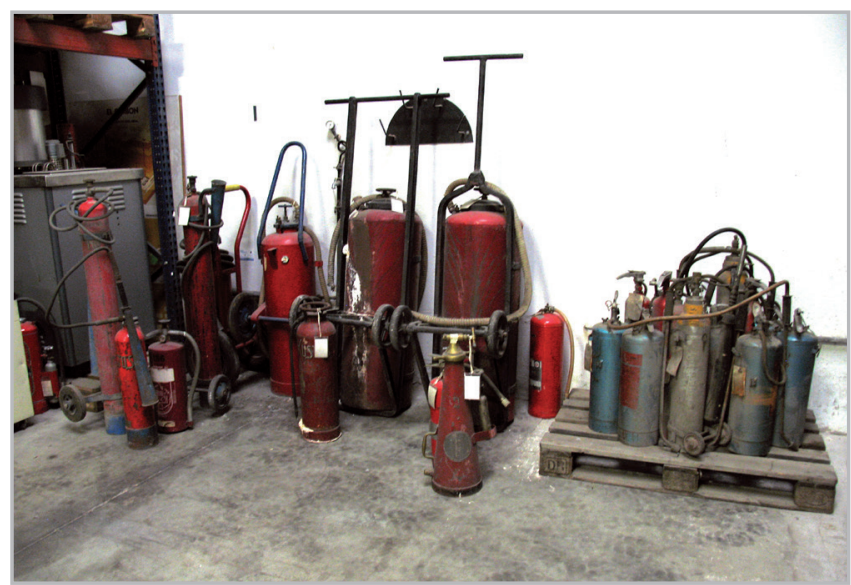

Figura 2.- Extintores preservados en el almacén paletizado del MUNCYT. 
El segundo grupo lo componen 22 extintores modernos de los años 2004 y 2006 [Figura 3] depositados en un patio exterior $y$, por ello, expuestos directamente a las condiciones climáticas. Puesto que todos tienen el mismo sistema (extintor y expelente) que algunos de los inventariados, probablemente no se integrarán en la colección histórica.

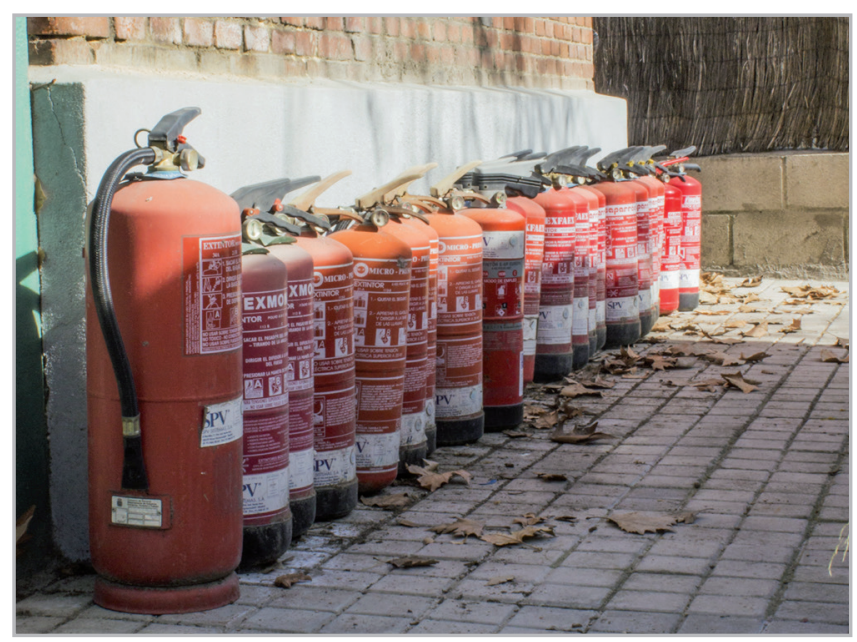

Figura 3.- Extintores almacenados en el exterior del almacén del MUNCYT.

En general, estos objetos se encuentran en un estado de conservación aceptable, aunque en algunos casos con problemas de corrosión. La hipótesis de partida es la existencia de una relación entre el tipo y mecanismo de funcionamiento del extintor y su conservación. Así, el contenido del extintor, podría suponer un problema para la conservación del metal, constituyendo un ejemplo de los problemas de compatibilidad entre los componentes de este tipo de objetos, que llevan a reflexionar sobre qué es lo que se debe conservar.

Para abordar esta cuestión, el estudio de esta colección plantea dos objetivos principales. El primer objetivo es la identificación y documentación de los extintores que componen la colección, respecto al origen, tipología y funcionamiento. El segundo objetivo se centra en la descripción del estado de conservación de cada extintor para establecer la posible relación entre el contenido con su preservación. Para ello se ha realizado un proceso de documentación de las patologías y del estado de conservación de todos los extintores, y un análisis de compuestos de corrosión y las sustancias que contienen para tratar de relacionarlos con el estado de conservación.

\section{Materiales y métodos}

La primera fase ha consistido en las labores de documentación y examen visual de las piezas de la colección, para determinar fabricantes, tipologías y contenido de las piezas. Estos datos, a pesar de su sencillez, resultan claves para identificar y entender los problemas de conservación que pueden presentar. Por ejemplo, para el estudio del contenido de los extintores ha sido indispensable la información que se extrae de las etiquetas o inscripciones; en aquellos en los que no aparece la información detallada, datos como la época del extintor, formato, piezas que lo componen permiten deducir esta información. Además, dos de los extintores, uno de agua y otro de $\mathrm{CO}_{2}$ (de la casa Defensa Contra Incendios y Antifyre respectivamente) pudieron abrirse para determinar el estado de conservación del interior, gracias a la ayuda de la empresa especializada SPV. Sistemas S.A.

Junto con las características de cada extintor se ha documentado su estado de conservación, tanto del metal como del recubrimiento y de sus distintos elementos, las palancas de activación, mangos, manometros, mangueras y válvulas [Figura 4].

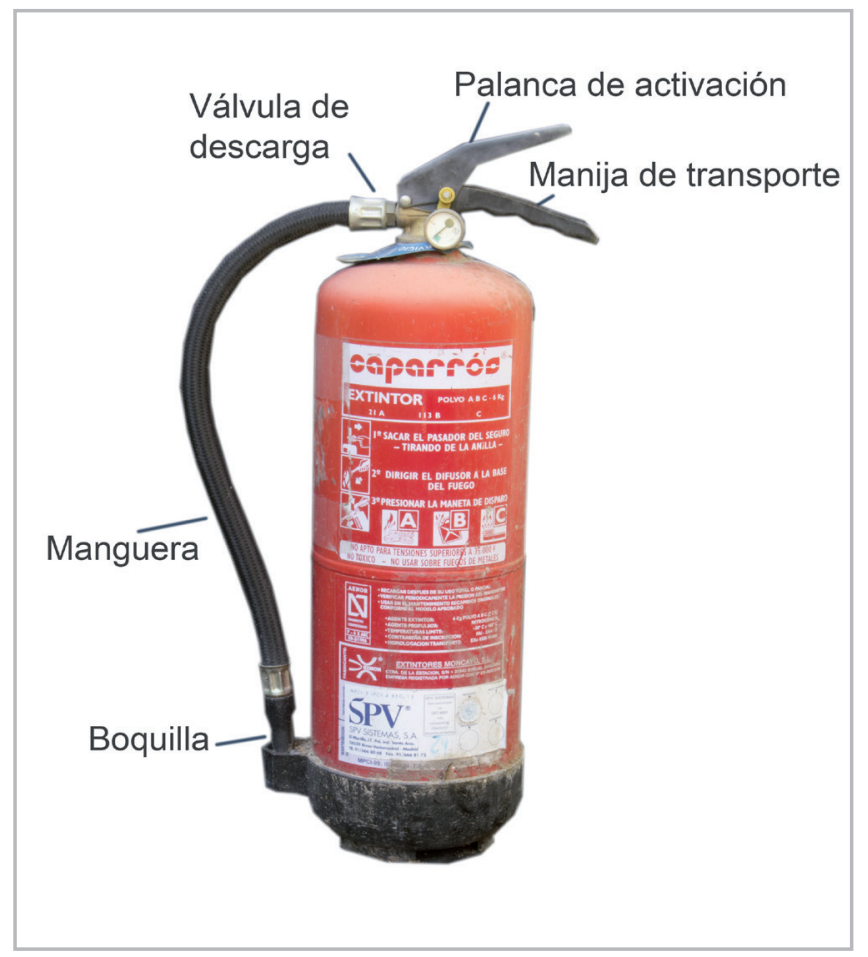

Figura 4.- Elementos de un extintor.

Para completar el estudio se han analizado un total de 9 muestras de 6 extintores [Figura 5], bien de productos de corrosión obtenidos a través de la toma de muestra de la superficie o bien del contenido del extintor. De estos 6 extintores, 4 se identifican mediantes su número de inventario, los otros dos han sido identificados como "extintor pequeño plateado" [figura 5e] y "extintor azul metálico" [Figura 5f]. A continuación, se relacionan los extintores y muestras analizadas:

- Extintor no 1986-006-2334 [Figura 5a]: restos y/o productos de corrosión en el interior del extintor [muestra E1]. 
- Extintor no 1986-006-2328 [Figura 5b]: se extrajo una primera muestra de los productos de corrosión que había en la válvula de salida [muestra E2]: Posteriormente el extintor se invirtió y se extrajo una cantidad importante del contenido, que se dividió en dos partes, una de productos se corrosión muy oscuros y otra de tono más claro [muestras E8 y E9]. - Extintor n 1991-019-0033 [Figura 5c]: del contenido del extintor, de polvo químico seco [muestra E3].

- Extintor no 1991-019-0035 [Figura 5d]: del contenido que había escapado a la superficie a causa de la perforación del metal de la botella [muestra E7].

- "Extintor pequeño plateado" [Figura 5e]: se tomó muestra de los productos de corrosión que había en el interior del cono de salida del extintor [muestra E4] y de productos de corrosión de color verde presentes en el exterior de la botella [muestra E5].

- "Extintor azul metálico" [Figura 5f]. El extintor azul también presentaba perforaciones en el metal. Por este motivo, se recogieron restos de productos de corrosión que había en la superficie del cilindro, cerca de las zonas donde el metal aparecía más deteriorado [muestra E6].

La composición elemental de las muestras tomadas se obtuvo por micro Fluorescencia de rayos X (FRX) con un equipo Fischerscope X-ray XUV 773 a 20kV, excepto para los elementos ligeros como $\mathrm{Al}, \mathrm{Si}, \mathrm{S}$ y $\mathrm{Cl}$ para los que se empleó $8 \mathrm{kV}$. Los análisis se realizaron a una presión de $10^{-3}$ mbares. La identificación de las fases cristalinas se realizó por difracción de rayos $\mathrm{X}$ (DRX) con un difractómetro Bruker AXS D8 Discover, equipado con anillo central de Euler con barrido en $X-Y$, con anticátodo de Co (40KV y $30 \mathrm{~mA}$ ) y detector lineal LynxEye. El rango en $2 \theta$ empleado fue de $10-$ $110^{\circ}$ con un paso de $0.015^{\circ}$ y tiempo por paso de $1.6 \mathrm{~s}$. Para el tratamiento de datos se empleó el software DiffractPlus EVA y Match 2 para identificación de compuestos y TOPAS versión 4.0, para el análisis cuantitativo Rietveld.

\section{Resultados y discusión}

\section{-Estado de conservación}

De los 56 extintores estudiados, la mitad presentaban signos visibles de corrosión. La otra mitad, entre los que se encuentran los del segundo grupo de extintores, no presenta signos visibles de corrosión aunque en algunos casos está oculta bajo el recubrimiento. La corrosión aparece principalmente en aquellos extintores más antiguos, lo que resulta lógico por su naturaleza metálica y el hecho de que no siempre hayan sido conservados en condiciones de museo por el tipo de objetos que representan. Al margen de este hecho, sí es posible apreciar diferencias en el grado de deterioro del metal en función del tipo de extintor -como se muestra más adelante-, y en muchos casos la alteración del metal está más localizada en las válvulas, seguramente provocada

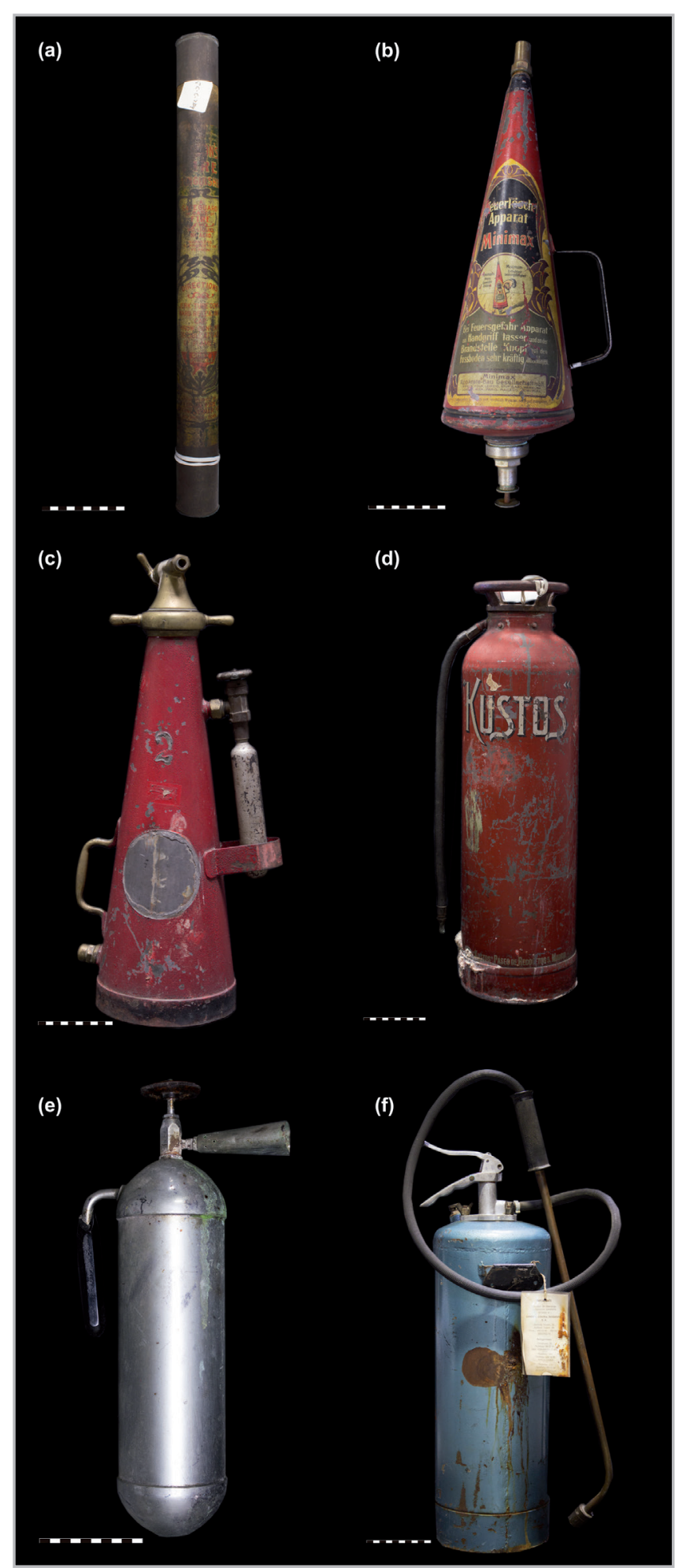

Figura 5.- Extintores analizados: a) Extintor no 1986-006-2334; b) Extintor no 1986-006-2328; c) Extintor n० 1991-019-0033; d) Extintor no 1991-019-0035; e) "Extintor pequeño plateado"; y f) "Extintor azul metálico".

por restos del contenido del extintor. El tipo de alteración que más se repite es aquella en la que extintores presentan unos productos de corrosión aislados en ciertas zonas y en los que la corrosión está concentrada en un punto, mientras que sólo unos pocos que presentan corrosión de forma generalizada [Figura 6]. 


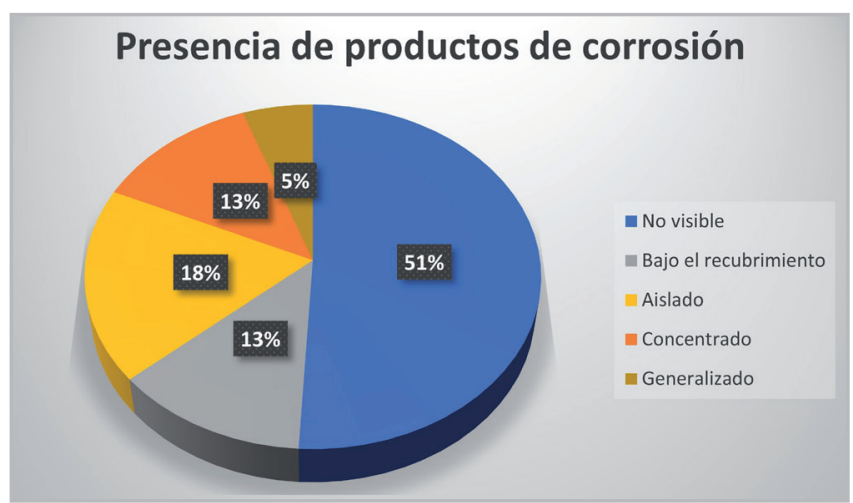

Figura 6.- Presencia de productos de corrosión en los extintores.

En cuanto al recubrimiento, las principales alteraciones observadas son pérdidas o levantamientos, incisiones y alteraciones cromáticas [Figura 7]. En aquellos extintores en los que ha habido alteraciones del metal patentes como las perforaciones o incisiones, el recubrimiento está muy dañado[Figura 8]. Se debe señalar que el grupo de extintores más modernos, cuyo contenido es de polvo químico seco, no hay una alteración significativa de la integridad de los recubrimientos. Sin embargo, sí que presentan la mayoría una alteración cromática, posiblemente provocada por su almacenamiento en el exterior.

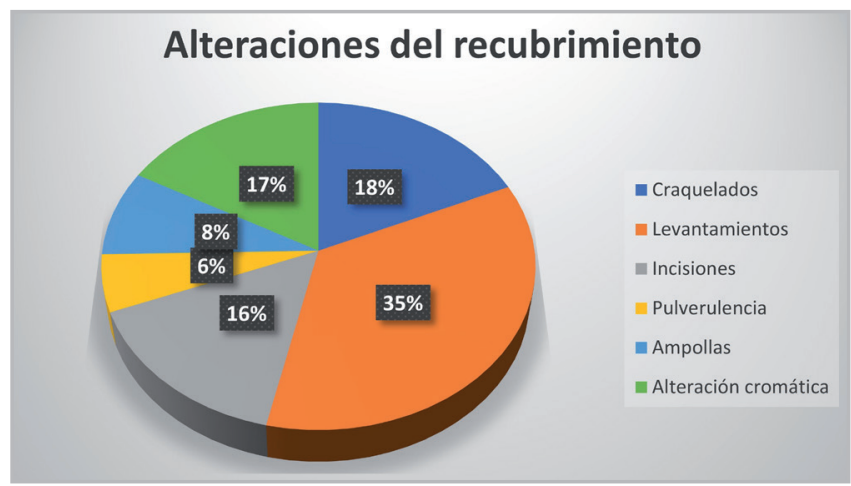

Figura 7.- Alteraciones observadas en los recubrimientos.

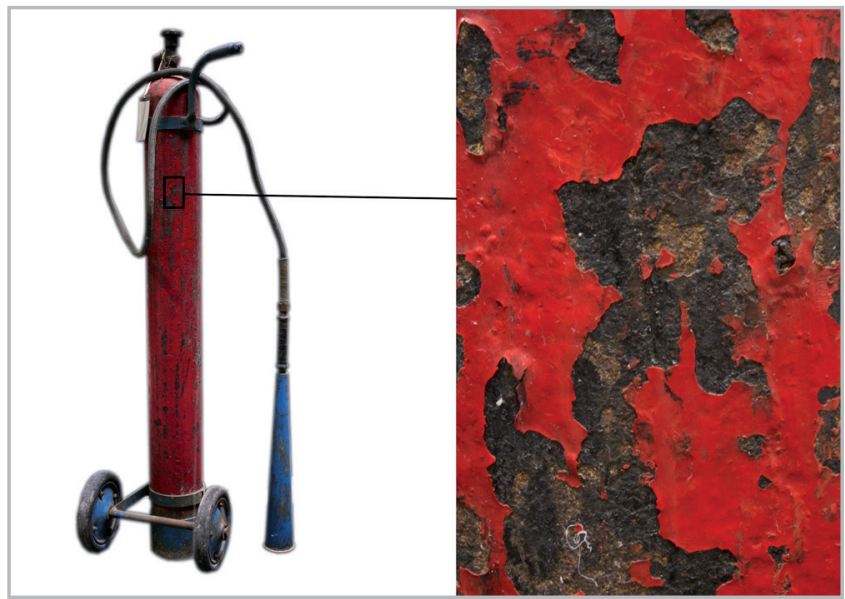

Figura 8.-Detalle del estado del recubrimiento en el extintor Kustos con no de inventario 1991/019/0040.

\section{-Tipos de extintores}

Se realizó una clasificación de los extintores, considerando varios criterios: compañía de fabricación, tipo de operación de activación y el tipo de contenido. Respecto al fabricante, se han identificado un total de 18 empresas diferentes. Algunas de estas compañías aún siguen distribuyendo extintores, por lo que pueden ser una fuente de información sobre las piezas, aunque hay otras que ya no están en activo.

Desde el punto de vista del agente extintor, se han identificado 5 tipos de producto: espuma, agua, $\mathrm{CO}_{2^{\prime}}$ polvo químico seco y bromuro, en 55 de los 56 extintores (en uno de ellos no ha sido posible identificar el agente extintor), y en base a cómo actúan el agente extintor y el gas expelente, se han clasificado los extintores en cuatro tipologías (Departamento capacitación 2004Cuerpo de bomberos 2011):

- Presurizados: El agente extintor y el gas expelente se encuentran en el mismo recipiente.

- Operados por cartuchos de gas: Este tipo de extintores presentan el agente extintor y el gas expelente en diferentes recipientes. Por tanto, para que salga el agente extintor propulsado se deben mezclar los componentes.

- Autogenerante: A este grupo pertenecerían aquellos extintores cuyo agente extintor experimenta una reacción química que genera su propia presión. Esto sucede sobre todo a los extintores de espuma química.

- Autoexpelente: En este caso el propio agente extintor genera su propia presión. En los extintores de $\mathrm{CO}_{2}$ el propio gas genera una presión determinada al quedar contenido dentro del recipiente.

En la Tabla 1 se resumen los extintores presentes en la colección del MUNCYT según fabricante y tipología.

\section{—Análisis del contenido y productos de corrosión}

La composición elemental analizada por FRX se muestra en la tabla 2 y las fases identificadas por DRX en la tabla 3.

En algunos casos se han identificado productos de corrosión del metal y en otros restos de los compuestos empleados como agente extintor o agente expelente que, junto con el resto de la información del extintor ha permitido conocer o confirmar la tipología del extintor.

- Extintor no 1986-006-2334: se trata de un extintor de naturaleza desconocida; el análisis de los restos del interior del extintor [muestra E1] se corresponde con productos de corrosión del hierro, identificándose akaganeita, lepidocrocita y goetita. Además se ha encontrado un 9,1\% de estaño, que está en forma de óxido. Los resultados de los análisis nos indican que el 
Tabla 1.-Tipología de extintores en la colección.En cursiva se señalan aquellos de los que se han tomado las muestras para su análisis.

\begin{tabular}{|c|c|c|c|c|}
\hline \multicolumn{5}{|c|}{ Autoexpelentes } \\
\hline$N^{\circ}$ Inventario & Fabricante & $\begin{array}{c}\text { Agente extintor/agente } \\
\text { expelente }\end{array}$ & $\begin{array}{l}\text { Unidades en la } \\
\text { colección }\end{array}$ & Ubicación \\
\hline & Antifyre & $\mathrm{CO}_{2}$ & 4 & Almacén - Paletizado \\
\hline $\begin{array}{l}1991-019-0040 \\
1991-019-0041\end{array}$ & Kustos & $\mathrm{CO}_{2}$ & 3 & Almacén - Paletizado \\
\hline- & Defensa contra incendios & $\mathrm{CO}_{2}$ & 2 & Almacén - Paletizado \\
\hline- & Desconocido & Bromuro & 2 & Almacén-Paletizado \\
\hline 2012-28-0001 & Parsi & Bromuro & 1 & Almacén - Compactos \\
\hline \multicolumn{5}{|c|}{ Autogenerantes } \\
\hline No Inventario & Fabricante & $\begin{array}{c}\text { Agente extintor/agente } \\
\text { expelente }\end{array}$ & $\begin{array}{l}\text { Unidades en la } \\
\text { colección }\end{array}$ & Ubicación \\
\hline $\begin{array}{l}1991-019-0035 \\
1991-019-0043 \\
1991-019-0038\end{array}$ & Kustos & Espuma & 3 & Almacén-Paletizado \\
\hline 1991-019-0039 & Antifyre & Espuma & 1 & Almacén - Paletizado \\
\hline $1986-006-2328$ & Minimax & Espuma & 1 & Almacén-compactos \\
\hline $1986-006-2334$ & Desconocido & Desconocido & 1 & Almacén-compactos \\
\hline \multicolumn{5}{|c|}{ Operados por cartucho de gas } \\
\hline No Inventario & Fabricante & $\begin{array}{c}\text { Agente extintor/agente } \\
\text { expelente }\end{array}$ & $\begin{array}{c}\text { Unidades en la } \\
\text { colección }\end{array}$ & Ubicación \\
\hline 1991-019-0042 & Total contra incendios & $\begin{array}{l}\text { Polvo Químico Seco/ } \mathrm{N}_{2} \\
\mathrm{OCO}_{2}\end{array}$ & 1 & Almacén - Paletizado \\
\hline 1991-019-0033 & Biosca & Polvo químico seco/ $\mathrm{CO}_{2}$ & 1 & Almacén - Paletizado \\
\hline- & Defensa contra incendios & Agua/ $\mathrm{CO}_{2}$ & 8 & Almacén - Paletizado \\
\hline \multicolumn{5}{|c|}{ Presurizados } \\
\hline$N^{\circ}$ Inventario & Fabricante & $\begin{array}{c}\text { Agente extintor/agente } \\
\text { expelente }\end{array}$ & $\begin{array}{l}\text { Unidades en la } \\
\text { colección }\end{array}$ & Ubicación \\
\hline $\begin{array}{l}1991-019-0030 \\
1991-019-0032\end{array}$ & Macoi & $\begin{array}{l}\text { Polvo químico seco/ } \mathrm{N}_{2} \mathrm{O} \\
\qquad \mathrm{CO}_{2}\end{array}$ & 2 & Almacén - Paletizado \\
\hline 1991-019-0031 & Extosa & Agua/ $\mathrm{N}_{2} \mathrm{OCO}_{2}$ & 1 & Almacén - Paletizado \\
\hline- & Ruimar & Polvo químico seco/ $\mathrm{N}_{2}$ & 2 & Almacén - Paletizado \\
\hline- & Areo-feus & Polvo químico seco & 1 & Almacén - Paletizado \\
\hline- & Caparros & Polvo químico seco & 7 & Exterior \\
\hline \multirow[t]{2}{*}{-} & E-6PEuropa & Polvo químico seco & 1 & Exterior \\
\hline & EXFAEX & Polvo químico seco & 4 & Exterior \\
\hline- & EXMON & Polvo químico seco & 3 & Exterior \\
\hline- & Gloria & Polvo químico seco & 1 & Exterior \\
\hline- & Micropress & Polvo químico seco & 5 & Exterior \\
\hline- & Firefox & Polvo químico seco & 1 & Exterior \\
\hline
\end{tabular}


Tabla 2.-Composición elemental de las muestras (\% en peso).

\begin{tabular}{|c|c|c|c|c|c|c|c|c|c|c|c|c|c|c|c|c|}
\hline & $\mathbf{F e}$ & $\mathbf{Z n}$ & $\mathbf{M n}$ & $\mathbf{S n}$ & $\mathbf{S}$ & $\mathbf{C l}$ & $\mathbf{C a}$ & $\mathbf{P b}$ & $\mathbf{N i}$ & $\mathbf{M o}$ & $\mathbf{C u}$ & $\mathbf{A l}$ & Si & $\mathbf{K}$ & $\mathbf{B r}$ & $\mathbf{R e s t o}$ \\
\hline E1 & 88,0 & 0,4 & 0,3 & 9,1 & 0,2 & 0,9 & 0,9 & - & - & - & - & - & - & - & - & 0,2 \\
\hline E2 & 68,9 & 0,8 & 0,2 & 2,7 & 15,3 & - & 0,9 & 4,3 & - & 6,0 & 0,9 & - & - & - & - & - \\
\hline E3 & 29,7 & 0,3 & - & - & - & - & 0,7 & - & 0,1 & - & 0,2 & 27,4 & 40,3 & 1,3 & & - \\
\hline E4 & 0,8 & 18,1 & - & - & 1,7 & 0,7 & 0,7 & - & 8,8 & - & 36,3 & - & 0,6 & 0,2 & 32,1 & - \\
\hline E5 & 0,4 & 18,2 & - & - & 3,7 & 1,0 & 1,3 & - & 16,0 & - & 30,4 & - & 1,0 & 0,2 & 27,8 & - \\
\hline E6 & 95,9 & 2,1 & 0,3 & - & 0,7 & - & 0,6 & - & - & - & - & - & - & - & - & - \\
\hline E7 & 22,5 & 0,3 & - & - & 73,7 & - & - & 1,9 & 0,1 & - & - & - & - & 1,5 & - & - \\
\hline E8 & 73,0 & 0,3 & 0,5 & - & 5,7 & - & - & 13,2 & - & - & 0,4 & - & - & - & - & 0,1 \\
\hline E9 & 56,5 & 0,4 & 0,3 & 19,4 & 17,4 & - & - & 6,0 & - & - & - & - & - & - & - & - \\
\hline
\end{tabular}

Tabla 3.-Fases indentificadas por DRX.

\begin{tabular}{|c|c|c|}
\hline Extintor & Muestra & Fases identificadas (DRX) \\
\hline $1986-006-2334$ & E1 & Akaganeita $(\beta-\mathrm{FeOOH})$, lepidocrocita $(\gamma-\mathrm{FeOOH})$, goetita $(\mathrm{a}-\mathrm{FeOOH})$, oxido de estaño $\left(\mathrm{SnO}_{2}\right)$. \\
\hline \multirow{3}{*}{$1986-006-2328$} & E2 & Goetita $(\mathrm{a}-\mathrm{FeOOH})$, szomolnokita $\left(\mathrm{FeSO}_{4} \cdot \mathrm{H}_{2} \mathrm{O}\right)$, rozenita $\left(\mathrm{FeSO}_{4} \cdot 4 \mathrm{H}_{2} \mathrm{O}\right)$, sulfato de $\mathrm{Pb}\left(\mathrm{PbSO}_{4}\right)$. \\
\hline & E8 & Goetita $(\mathrm{a}-\mathrm{FeOOH})$, anglesita $\left(\mathrm{PbSO}_{4}\right)$, coquimbita $\left(\mathrm{Fe}_{2}\left(\mathrm{SO}_{4}\right)_{3} \cdot 9 \mathrm{H}_{2} \mathrm{O}\right)$. \\
\hline & E9 & Rozenita $\left(\mathrm{FeSO}_{4} \cdot 4 \mathrm{H}_{2} \mathrm{O}\right)$, anglesita $\left(\mathrm{PbSO}_{4}\right)$, szomolnokita $\left(\mathrm{FeSO}_{4} \cdot \mathrm{H}_{2} \mathrm{O}\right)$. \\
\hline 1991-019-0033 & E3 & $\begin{array}{l}\text { Cuarzo }\left(\mathrm{SiO}_{2}\right) \text {, nahcolita }\left(\mathrm{NaHCO}_{3}\right) \text {, caolinita }\left(\mathrm{Al}_{2} \mathrm{Si}_{2} \mathrm{O}_{5}(\mathrm{OH})_{4}\right) \text {, lizardita }\left(\mathrm{Mg}_{3} \mathrm{Si}_{2} \mathrm{O}_{5}(\mathrm{OH})_{4}\right) \text {, nacrita } \\
\left(\mathrm{Al}_{2} \mathrm{Si}_{2} \mathrm{O}_{5}(\mathrm{OH})_{4}\right) \text { y goetita }(\mathrm{a}-\mathrm{FeOOH}) \text {. }\end{array}$ \\
\hline \multirow{2}{*}{ Extintor pequeño plateado } & E4 & $\begin{array}{l}\text { Paramelaconita }\left(\mathrm{Cu}^{1+}{ }_{2} \mathrm{Cu}^{2+}{ }_{2} \mathrm{O}_{3}\right) \text {, hidroxibromuro de cobre }\left(\mathrm{Cu}_{2} \mathrm{Br}(\mathrm{OH})_{3}\right) \text { retsergita } \mathrm{NiSO}_{4} \cdot 6\left(\mathrm{H}_{2} \mathrm{O}\right) \text { y } \\
\text { nitrato de niquel hidratado }\left(\mathrm{Ni}\left(\mathrm{NO}_{3}\right)_{2} \cdot 6 \mathrm{H}_{2} \mathrm{O}\right)\end{array}$ \\
\hline & E5 & $\begin{array}{l}\text { Paramelaconita }\left(\mathrm{Cu}^{1+}{ }_{2} \mathrm{Cu}^{2}{ }_{2} \mathrm{O}_{3}\right) \text {, hidroxibromuro de cobre }\left(\mathrm{Cu}_{2} \mathrm{Br}(\mathrm{OH})_{3}\right) \text {, nitrato de níquel hidratado } \\
\left(\mathrm{Ni}(\mathrm{NO} 3)_{2} \cdot 6 \mathrm{H}_{2} \mathrm{O}\right) \text {, brochantita }\left(\mathrm{Cu}_{4}(\mathrm{SO})_{4}(\mathrm{OH})_{6}\right)\end{array}$ \\
\hline Extintor azul metálico & E6 & Goetita (a-FeOOH), lepidocrocita ( $\gamma-\mathrm{FeOOH})$. \\
\hline 1991-019-0035 & E7 & $\begin{array}{l}\text { Thenardita }\left(\mathrm{Na}_{2} \mathrm{SO}_{4}\right) \text {, burkeita }\left(\mathrm{Na}_{6}\left(\mathrm{CO}_{3}\right)\left(\mathrm{SO}_{4}\right)_{2}\right) \text {, carbonato sódico } \mathrm{Na}_{2} \mathrm{CO}_{3^{\prime}} \\
\text { trona }\left(\mathrm{Na}_{3}\left(\mathrm{HCO}_{3}\right)\left(\mathrm{CO}_{3}\right) \cdot 2 \mathrm{H}_{2} \mathrm{O}\right) \text { y nahcolita }\left(\mathrm{NaHCO}_{3}\right) \text {. }\end{array}$ \\
\hline
\end{tabular}

material en que estaba fabricado es hojalata (lámina de acero recubierta de estaño). La presencia de cloro en altas cantidades es responsable de la formación de la akaganeita, y probablemente su origen se encuentre en algún compuesto (desconocido) del agente extintor. La lepidocrocita $y$, sobre todo, la akaganeita, son compuestos inestables que nos indican un proceso de corrosión activo, lo que añadido al alto contenido de cloro, muy agresivo para el hierro, hacen recomendable una conservación de esta pieza en condiciones de baja humedad.

- Extintor no 1986-006-2328: la muestra E2, extraída de la válvula de salida del extintor se compone mayoritariamente de hierro con un $68,9 \%$, siendo también apreciable la presencia de molibdeno $(6,1 \%)$ y azufre $(15,3 \%)$. Los productos de corrosión en esta muestra incluyen productos de degradación del hierro, como la goetita, pero también sulfatos de hierro como la szomolnokita y la rozenita, o un sulfato de plomo. En el interior del extintor (muestras E8 y E9) se identifican también productos de degradación del hierro como goetita, y sulfatos de plomo y de hierro. La presencia de azufre formando sulfatos metálicos puede atribuirse a los componentes de la espuma química que utilizaban este tipo de extintores, incluyendo ácido sulfúrico. La presencia de plomo se explicaría también por su uso tradicional como contenedor para este ácido.

- Extintor no 1991-019-0033: En la muestra E3, además de un $29,7 \%$ de hierro, los compuestos mayoritarios son silicio $(40,3 \%)$ y aluminio $(27,4 \%)$, acompañados de pequeñas cantidades de otros elementos. Esta composición junto con los datos de DRX nos indica que la muestra está compuesta fundamentalmente por silicatos y aluminosilicatos (cuarzo, caolinita) que constituyen el polvo químico del agente extintor. El único producto de degradación del contenedor de hierro (goetita) aparece en cantidades pequeñas, y es un compuesto relativamente estable.

- Extintor no 1991-019-0035: la muestra E7 está recogida de los restos presentes en la base del extintor, como 
consecuencia de la fuga que ha sufrido por la perforación del metal. Está compuesto mayoritariamente por azufre $(73,7 \%)$, seguido del hierro $(22,5 \%)$ y en menor porcentaje, plomo (19\%), mientras que los datos de difracción muestran sobre todo sulfatos y carbonatos de sodio. Estos resultados concuerdan con el hecho de que se trate del contenido de un extintor de espuma, que funcionase por inversión. Estos compuestos determinan que el funcionamiento (similar al 1986-006-2328) se basaría en la reacción entre un ácido, probablemente sulfúrico y contenido en un recipiente de plomo, con una base de carbonato de sodio.

- "Extintor pequeño plateado": en las muestras E4 y E5, correspondientes al extintor de bromuro de color plateado, se han encontrado principalmente cobre, zinc, niquel y bromo. La presencia de cobre como elemento principal, acompañado de $\mathrm{Zn}$ y $\mathrm{Ni}$ en cantidades significativas nos indica que este extintor estaría realizado seguramente en latón y presentaría un acabado niquelado, responsable del color plateado. El análisis de los productos de corrosión situados en el cono de salida (E4) y en el exterior (E5) ha dado como resultado la presencia de óxidos, hidroxibromuro de cobre, sulfatos y nitratos de níquel. Excepcionalmente también se ha identificó la brochantita $\left(\mathrm{Cu}_{4}(\mathrm{SO})_{4}(\mathrm{OH})_{6}\right)$. Los nitratos, bromuros y sulfatos pueden ser atribuidos al contenido del extintor que resulta agresivo para el metal que constituye el contenedor.

- "Extintor azul metálico". La muestra E6 de los productos de corrosión que se ha formado en la perforación de uno de los extintores de agua del fabricante de Defensa Contra Incendios, se compone de goetita, lepidocrocita y magnetita. En esta muestra, se aplicó el método Rietveld para obtener las proporciones de los compuestos. Bajo este, se ha obtenido una proporción alta de goetita (por encima de 97\%), el resto de cantidades fueron de lepidocrocita y magnetita $\left(\mathrm{Fe}_{3} \mathrm{O}_{4}\right)$. Estos son típicos productos de corrosión del hierro por exposición a humedad, y no aparecen otros elementos atribuibles al contenido del extintor.

A partir del estudio de las características de los extintores y la observación de las patologías identificadas en cada uno de ellos, se puede apreciar que efectivamente existe una relación entre ambos.

En el caso de los extintores de $\mathrm{CO}_{2}$, el contenido es únicamente un gas comprimido. Dentro de la botella no hay un agente que pueda oxidar, ni electrolitos que puedan permitir que se desencadene la corrosión del metal desde el interior. Gracias al desmontaje de uno de los extintores del fabricante Antifyre este planteamiento fue verificado, al determinar que el estado del metal del interior de la botella era bastante bueno.

Los de polvo químico seco en principio también deberían ser estables, al contener estos polvos y el agente expelente, que puede ser $\mathrm{N}_{2} \mathrm{O}$, de nuevo, el $\mathrm{CO}_{2}$. El análisis de la muestra E3 nos indica que el contenido de estos extintores es a base de silicatos. Por consiguiente, no debería suponer ningún problema de corrosión en el metal. Estos extintores son los que presentan mejor estado de conservación.

Los extintores que presentan mayores problemas de conservación son los extintores de espuma y los de agua. Aunque en muchos de ellos no se aprecian signos de corrosión externos, que pueden estar bajo el recubrimiento, los casos más extremos se encuentran en este grupo, donde cinco extintores presentan la perforación del metal (tres de espuma y dos de agua), por un proceso de corrosión severa originada en el interior del extintor por el contenido del mismo. En algunos de los extintores de espuma el contenido ha salido al exterior a través de las perforaciones del metal [Figura 9]. El análisis del contenido de estos extintores [muestra E7] detecta la presencia de compuestos de tipo sulfato y bicarbonatos lo que permite deducir que la espuma se producía a partir de reacciones ácido-base y, por tanto, se trata de sustancias corrosivas para el metal.

En los extintores de agua la corrosión sólo es visible en aquellos en los que se han producido perforaciones, sin embargo, el desmontaje de uno de estos extintores, del fabricante Defensa Contra Incendios, mostró que interior estaba totalmente corroído. El botellín de presión adosada, presentaba el recubrimiento lleno de ampollas debido al estado avanzado de corrosión producido por el ambiente interno con el agua [Figura 10].

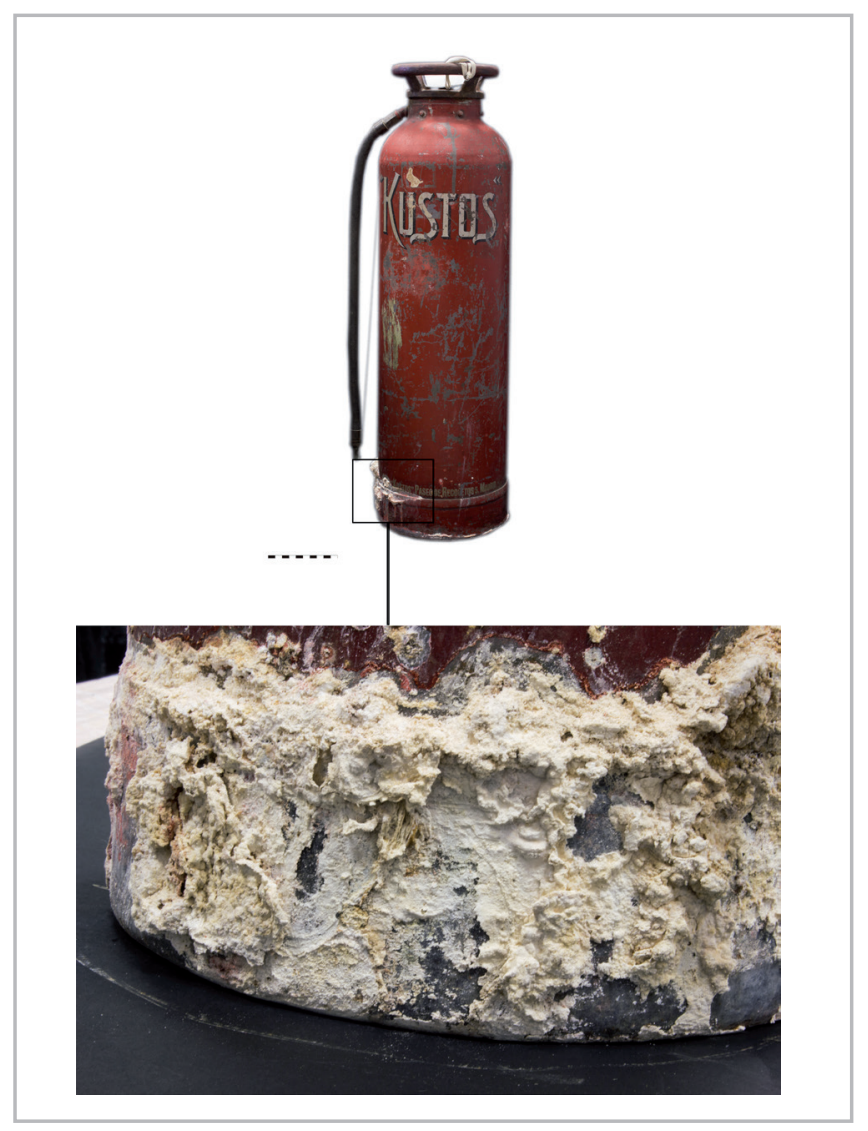

Figura 9.- Restos de productos procedentes del interior. 


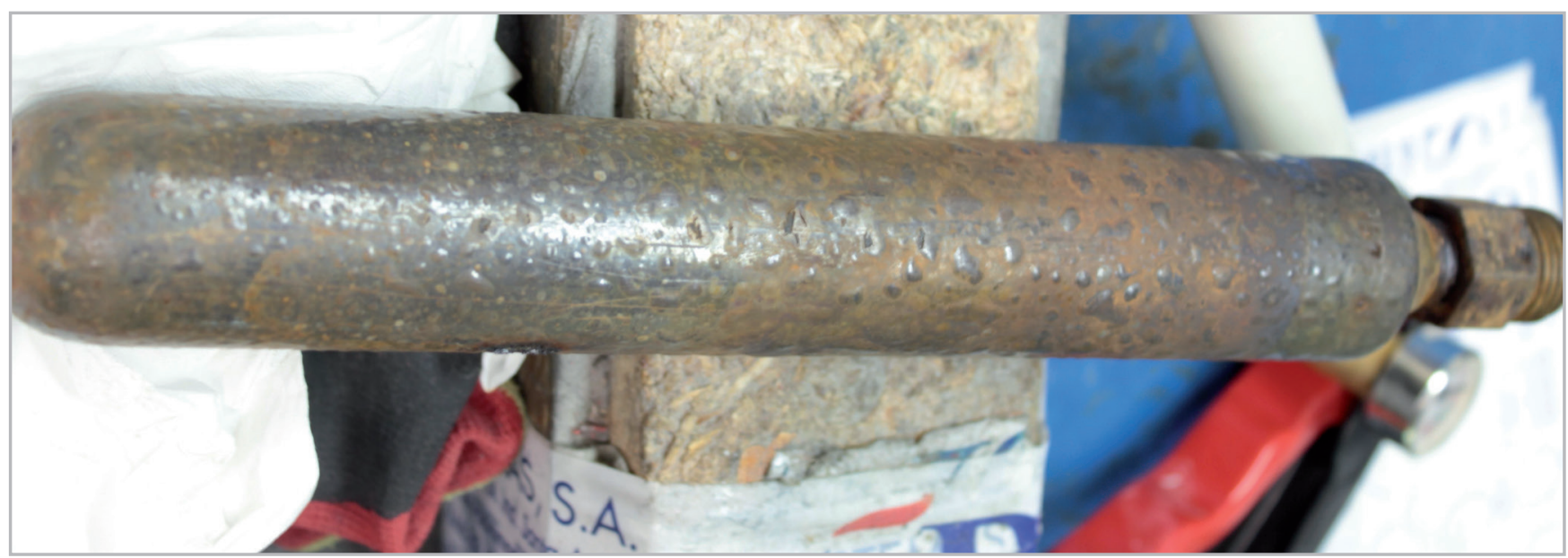

Figura 10.- Corrosión generalizada y ampollamiento del recubrimiento en el botellín de presión del extintor de agua desmontado.

En estos casos, en que el proceso de deterioro se origina en el interior por reacción del envase con el contenido del extintor, un factor a considerar es si han sido utilizados o no. En un extintor completamente lleno y cerrado, la cantidad de oxígeno en el interior es limitada, y una vez consumido, la reacción catódica se detiene $y$, con ello, el proceso de corrosión. Por el contrario, cuando el extintor ha sido utilizado y hay contacto con el exterior, se permite la entrada de oxígeno, reactivando el proceso de degradación. Aunque se sospecha que en los extintores estudiados este efecto puede haber sido importante, los datos disponibles no permiten establecer una correlación inequívoca entre la corrosión más severa y el estado de uso del extintor.

Por lo tanto, volviendo al punto planteado al inicio del trabajo, los resultados en el diagnóstico han demostrado que -entre otros factores- la tipología del extintor está relacionada con la conservación del objeto. Específicamente los extintores de agua y espuma son los que presentan problemas más acusados por la naturaleza de los productos que contienen, lo que plantea la cuestión de si se pueden conservar completos o es necesario vaciar los productos de su interior. La presencia de agua o de compuestos químicos agresivos es motivo de degradación del metal y los daños que produce son progresivos y severos, comprometiendo inevitablemente la conservación del objeto. Estando además su origen en el interior, no resulta posible limitar su deterioro por medio de actuaciones de conservación preventiva sobre las condiciones ambientales de conservación. Por el contrario, en los extintores con un contenido no agresivo para el metal, el deterioro se origina en el exterior, por lo que una adecuada limpieza y un control de las condiciones de conservación pueden ser eficaces para frenar su deterioro.

\section{Conclusiones}

Además de la escasa valoración social de los bienes que lo componen, la complejidad de los materiales que componen el patrimonio científico-técnico suponen un desafío importante para su conservación. En el caso presentado de la colección de extintores del Museo Nacional de Ciencia y Tecnología, la clasificación realizada ha permitido identificar y clasificar los objetos en base a la tipología de agente extintor utilizado, así como identificar la abundancia y tipo de patologías que sufren.

Los análisis por fluorescencia de rayos $\mathrm{X}$ y difracción de rayos $X$ han permitido identificar los productos de corrosión formados, e identificar en qué casos están relacionados con el contenido del extintor.

Se ha demostrado que los extintores a base de espuma -que contienen sustancias ácidas- y los de agua están especialmente deteriorados por procesos de corrosión iniciados desde el interior de los mismos. En estos casos, para asegurar una correcta conservación resultaría necesario vaciar y limpiar de manera exhaustiva el interior, aunque con ello se sacrifique parte del material original del objeto. No hacerlo supondría un mayor daño a medio plazo, pues se produciría la perdida irremisible de los bienes.

\section{Agradecimientos}

A Antonio Sanz, jefe técnico del grupo SPV Sistemas. Al Ministerio de Ciencia, Innovación y UniversidadesAgencia Estatal de Investigación por la financiación del proyecto COMPACT (HAR2017-89911-R) y a la Comunidad de Madrid y Fondos Estructurales y de Inversión Europeos por la financiación del proyecto TOP-HERITAGE CM (S2018/ NMT_4372). A la Plataforma Temática Interdisciplinar "Patrimonio Abierto: Investigación y Sociedad" (PTI-PAIS) del CSIC por el apoyo profesional.

\section{Referencias}

ASHTON, J., HALLAM, D. (1990). "The conservation of functional objects -An ethical dilemma", AICCM Bulletin, 16(3): 19-26. https:// doi.org/doi: 10.1179/bac.1990.16.3.003 
BALL, S. (2009). “Larger \& Working Objects: a guide to standards in their preservation and care", Collection trust. Disponible en: $\quad$ http://326gtd123dbk1xdkdm489u1q.wpengine.netdnacdn.com/wp-content/uploads/2017/01/Larger-and-workingobjects-updated-003044.pdf [consulta: 13/06/2017].

BEET, C., COULLS, A. (2010). "Is it safe? - balancing conservation, operation and display of rail vehicles at the National Railway Museum", en Proceedings of the International Conference Big Stuff, 2010. Duxford, UK. Disponible en: https://bigstuff.omeka.net/ items/show/81

BRUNOTT, M. et al. (2010). "Conservation maintenance programs for functional objects", en Mardikinan, P. et al. (Eds.), Proceedigns of Metal 2010. 7th interim meeting of the ICOM-CC Metals Working Group. Clemson University, South Carolina, USA, 421-429.

DEPARTAMENTO CAPACITACIÓN 2004- Cuerpo de bomberos (2011). "1. Seguridad contra incendios. Curso de utilización de extintores". Disponible en: http://www.fullserviceadm.com/01MANUAL-DE-EXTINTOR.pdf [consulta: 03/08/2017].

GUAL VIA, M. (2015). "Los metales en los museos de Ciencia y Técnica", ICOM digital, 10: 72-76. Disponible en: https://issuu. com/icom-ce librovirtual/docs/icom-ce digital 10 [consulta: 26/07/2017].

HALLAM, D. (2007). “Ethical and philosophical issues of operating of Functional Objects; a Developing Approach", en Big Stuff 2007: Proceedins of the International Conference. Bochum, Alemania, 3843.

HENDERSON, J., WALLER, R. (2016). "Effective preservation decision strategies", Studies in Conservation, 61(6): 308-323. https:// doi.org/10.1179/2047058415Y.0000000019

LEAL PÉREZ CHAO, J. (2016). “Dificultades en la conservaciónrestauración del Patrimonio Industrial Mueble", en Jornadas de conservación- restauración del Patrimonio Industrial Mueble, Asociación de Conservadores y Restauradores de Bienes Culturales del Principado de Asturias. Candás, 61-71.

BARRIO MARTíN, J. et al. (2015). "Proyecto Inventario y Catalogación del Patrimonio Histórico-Tecnológico de Telefónica", en Barrio Martín, J. y Cano, E. (Eds.), Metal España 2015, Actas de II Congreso de Conservación y Restauración del Patrimonio Metálico, 293-299.

BRAMBILLA, L., et al. (2016). "Condition of Cans in Collections: A Challenge in Conservation", en Menon, R. et al. (Eds.) Proceedings of Metal 2016, Interim Meeting of the ICOM-CC Metals Working Group IGNCA and ICOM-CC, New Delhi India, 266-274.

DAVISON, E.M. (1911). Process of extinguisbng fires. U.S. Patent n. 1.010.870. Disponible en: https://patentimages.storage. googleapis.com/b3/e9/d4/5b772b23063063/US1010870.pdf

HALL, C.W. (2000). Biographical Dictionary of People in Engineering. From the Earliest Records to 2000. Purdue University Press.
MACLEOD, C. (1988). Inventing the Industrial Revolution: The English Patent System, 1660-1800. Cambridge: Cambridge University Press. https://doi.org/10.1017/CBO9780511522673

MITCHELL, G. (2015). "Application of the Burra Charter to large technology objects: a freelance conservator's experiences", en Wain, A. (Ed.) Proceedings of Big Stuff 2004, Imperial War Museum, Camberra, Australia.

PACHECO MUÑOZ, M. F. (2007). "Los museos de ciencia y la divulgación", Redes. Buenos Aires: Universidad Nacional de Quilmes. Disponible en: https://www.redalyc.org/ pdf/907/90702507.pdf [consulta: 13/06/2017].

PLAN NACIONAL DE PATRIMONIO INDUSTRIAL (2015). Ministerio de Educación, Cultura y Deporte. Disponible en: http://www. culturaydeporte.gob.es/planes-nacionales/dam/jcr:88a504bda083-4bb4-8292-5a2012274a8c/04-maquetado-patrimonioindustrial.pdf

THURROWGOOD, D. y HALLAM, D. L. (2004). "Preserving significance: Why the journey mattered more than the car", Heritage New Zealand, (89): 10-16. Disponible en: https://www. awm.gov.au/events/conference/bigstuff/index.asp.

TICCIH y ICOMOS (2003). “Carta de Nizhny Tangil sobre Patrimonio Industrial".

WAIN, A. (2017). "The Importance of Movement and Operation as Preventive Conservation Strategies for Heritage Machinery", Journal of American Institute for Conservation, 56(2): 81-95. https:// doi.org/10.1080/01971360.2017.1326238

\section{Autor/es}

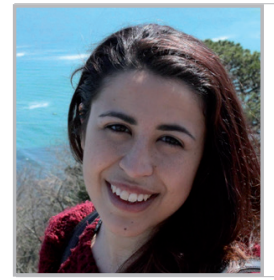

Andrea Díaz-Cortés
anddi91113@gmail.com
Institut Català de Paleoecologia Humana
i Evolució Social, Zona Educacional 4,
Campus Sescelades URV (Edifici W3),
Tarragona.

Graduada en Conservación y Restauración del Patrimonio Cultural en la Universidad Complutense de Madrid en 2015. En 2017 finalizó el Máster en Diagnóstico del Estado de Conservación del Patrimonio histórico de la Universidad Pablo de Olavide (UPO), a través del cual realizó el estudio sobre los extintores históricos del Museo de Ciencia y Tecnología y las prácticas en el Centro Nacional de Investigaciones Metalúrgicas (CENIM). Desde 2018 realiza su tesis doctoral a través de un contrato predoctoral FPU financiado por el Ministerio de Ciencia, Innovación y Universidades en el Institut Català de Paleocologia i Evolució Social (IPHES). El principal objetivo es el evaluar la eficacia a través del estudio de la penetración y capacidad de cohesión de diferentes consolidantes y métodos de aplicación en huesos arqueológicos, enfocándolo en los 
yacimientos de la Sierra de Atapuerca (Burgos) y Barranc de la Boella (Tarragona). El 2019 finalizó el Máster de Arqueología de CuaternarioyEvolución Humana de la Universitat RoviraiVirgili. Ha colaborado como conservadora-restauradora en el Museo Arqueológico Regional de Madrid, así como en varios yacimientos arqueológicos del Pleistoceno en España.

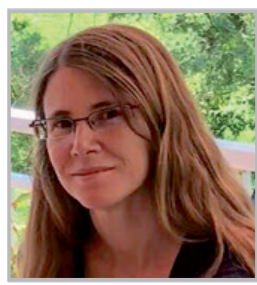

\section{Blanca Ramírez Barat}

blanca.ramirez@csic.es

Centro Nacional de Investigaciones Metalúrgicas (CENIM) - Consejo Superior de Investigaciones Científicas (CSIC).

Química y restauradora de formación, actualmente es investigadora postdoctoral en el grupo "Corrosión Atmosférica y Patrimonio Cultural (CAPAC)" en el Centro Nacional de Investigaciones Metalúrgicas (CENIM-CSIC). Su línea principal de investigación se centra en la aplicación de técnicas electroquímicas a la conservación y diagnóstico del patrimonio cultural metálico. Ha participado en diversos proyectos de investigación nacionales y europeos, así como en redes y otras iniciativas relacionadas con Ciencia del Patrimonio como la red TechnoHeritage, el Plan Nacional de Investigación en Conservación (PNIC) y el Observatorio para la investigación en conservación, la Plataforma Temática Interdisciplinar Patrimonio Abierto: Investigación y Sociedad, PTI-PAIS (o el Nodo Español de la Infraestructura Europea de Investigación en Ciencia del Patrimonio (ERIHS.es). https://orcid.org/0000-0001-5306-4057

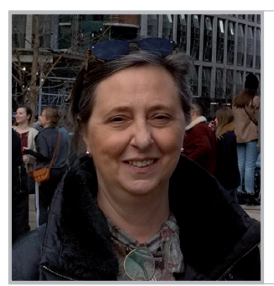

\section{Joaquina Leal Perez-Chao}

joaquina.leal@muncyt.es

Museo Nacional de Ciencia y Tecnología. Fundación Española para la Ciencia y la Tecnología, MUNCYT.

Restauradora titulada por la Escuela de Conservación y Restauración de Bienes Culturales de Madrid en 1987. En 2007 realizó en la Facultad de Ciencias de la Universidad Autónoma de Madrid, UAM, el "Máster en Arqueometría", y en 2009 el "Máster en Conservación de Bienes Culturales: Conservación, Restauración y Exposiciones" de la Universidad Complutense de Madrid, y es Experta en Conservación Preventiva en Museos, Exposiciones y Monumentos por la Universidad a Distancia de Madrid (UDIMA). $\mathrm{Ha}$ trabajado en diferentes museos dependientes de la administración pública y colaborando con el IPCE en muchas ocasiones, tanto en trabajos de conservación y restauración como en proyectos de investigación. Desde julio de 2009 es la restauradora del Museo Nacional de Ciencia y Tecnología, MUNCYT, donde ha podido participar en las labores de Conservación previas a la inauguración de las sedes de A Coruña (2012) y Alcobendas, Madrid, (2014), así como en todas las tareas del departamento relacionadas con la colección.

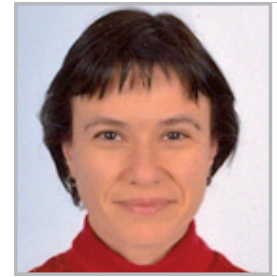

Irene Llorente

irene@cenim.csic.es

Centro Nacional de Investigaciones Metalúrgicas (CENIM) - Consejo Superior de Investigaciones Científicas (CSIC).

Irene Llorente comenzó su carrera investigadora en el año 1999 en el Instituto de Ciencias de la Construcción "Eduardo Torroja". La investigación que llevó a cabo estaba enfocada en los siguientes campos: Caracterización del transporte de iones a través del hormigón; Estudio de la durabilidad de hormigones y morteros; y Degradaciónnaturalyaceleradadelhormigónporlaaccióndelagua. En el año 2006 comenzó a trabajar en el Centro Nacional de Investigaciones Metalúrgicas (CENIM) como responsable técnico del Laboratorio de Caracterización de Superficies a cargo de las técnicas de Espectroscopía Fotoelectrónica de Rayos X (XPS) y Microscopía de Fuerzas Atómicas (AFM). Desde el año 2014 se hizo cargo, también como responsable técnico, del Laboratorio de Difracción de Rayos $X$ a cargo de los equipos de Difracción de Rayos X (DRX) y Fluorescencia de Rayos X (XRF). Ambos laboratorios tienen la certificación según la norma ISO 9001, siendo ella la responsable de calidad. Adicionalmente, ha participado en varios proyectos de investigación, con las siguientes temáticas: Desarrollo de recubrimientos protectores contra la corrosión en aleaciones de magnesio; Desarrollo de métodos de encapsulado para liberación controlada de inhibidores de corrosión para la protección de armaduras en hormigón; Estudio del efecto de la adición de Cr sobre la corrosión de los aceros TWIP; y Caracterización de recubrimientos de grafeno en aleaciones de $\mathrm{CoCr}$. Irene Llorente ha publicado 42 artículos y ha participado en 10 proyectos nacionales, 4 proyectos europeos y 32 contratos con empresa y tiene una amplia experiencia en la caracterización de materiales mediante técnicas como XPS, AFM, DRXY XRF.

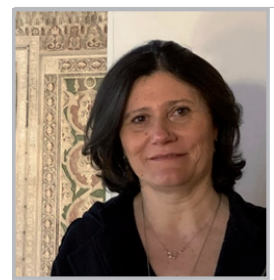

Marián del Egido,

marian.delegido@cultura.gob.es

Directora del Centro de Conservación y Restauración de Filmoteca Española.

Marián del Egido, física y conservadora de museos, se incorporó al Instituto del Patrimonio Cultural de España (IPCE) en 2000, después de haber trabajado durante cuatro años en el Museo Nacional de Ciencia y Tecnología en la catalogación e investigación de las colecciones. Fue Responsable del Área de Laboratorios del IPCE hasta 2012, cuando fue nombrada Jefa de Área de Investigación y Formación. En estas funciones, fue responsable del establecimiento de la estrategia departamental y prioridades en el marco de las ciencias aplicadas a la conservación del patrimonio cultural y del programa formativo en ciencias de la conservación. Durante estos años ejerció de coordinadora del Plan Nacional de Investigación en Conservación, coordinadora de los centros de conservación integrados en la red Technoheritage, Red española dedicada a la ciencia y la tecnología para la 
conservación del patrimonio cultural, y coordinadora del "Plan de conservación preventiva y accesibilidad de la cueva de Altamira Cave(2012-2014)".FuemiembrodelConsejo de ICCROMentre2005 y 2013, siendo vicepresidenta de ese Consejo entre 2011 y 2013. Ha formado parte del Spanish National Consultation Panel of the Executive Board en el Joint Programming Initiative "Cultural Heritage and Global Change: a challenge for Europe", 2011-2013. En febrero de 2014 fue nombrada directora del Museo Nacional de Ciencia y Tecnología, donde lideró el plan museográfico y el programa educativo de la nueva sede del Museo, inaugurada en diciembre de 2014, así como su programa expositivo. Ha sido miembro del Jurado del Premio Princesa de Asturias 2016 en la modalidad de Ciencia y Tecnología. Desde septiembre de 2019 es la directora del Centro de Conservación y Restauración de Filmoteca Española.

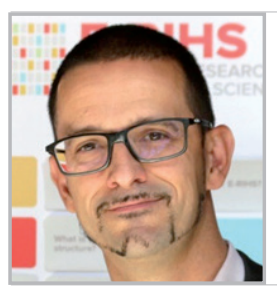

\section{Emilio Cano \\ ecano@cenim.csic.es \\ Centro Nacional de Investigaciones Metalúrgicas (CENIM) - Consejo Superior de Investigaciones Científicas (CSIC).}

El Dr. Emilio Cano es Científico Titular del CSIC, investigador principal del grupo "Corrosión y Protección de Metales en Patrimonio Cultural y Construcción" (COPAC) del Centro Nacional de Investigaciones Metalúrgicas. Licenciado en Bellas Artes (especialidad Restauración), por la UCM, obtuvo su doctorado en el año 2001 (UCM), habiendo realizado una estancia en el Canadian Conservation Institute. Sus líneas de investigación se enfocan al estudio de la corrosión y sistemas de protección del Patrimonio Cultural metálico, corrosión atmosférica en interiores de museos y exposiciones y técnicas electroquímicas. Esta labor se ha visto plasmada en más de 125 publicaciones científicas (89 son artículos en revistas científicas incluidas en el SCI/SCOPUS), más de 100 comunicaciones a congresos, ha participado en 37 proyectos de investigación nacionales e internacionales $\left(6^{\circ}\right.$ y 70 Programa Marco y Horizonte 2020 de la UE), siendo IP en 14 de ellos en los últimos 10 años; así como numerosos contratos de investigación y apoyo tecnológico con empresas e instituciones. En ellos, ha colaborado con instituciones como el Instituto del Patrimonio Cultural de España, Patrimonio Nacional, Museo del Prado, Museo Arqueológico Nacional, Museo Guggenheim Bilbao, Museo Oteiza, Museo Nacional de Ciencia y Tecnología, etc). Es Assistant Coordinator del Grupo de Metal del ICOMCC; Coordinador de la "Red de Ciencia y Tecnología para la Conservación del Patrimonio Cultural (TechnoHeritage); Fellow del International Institute of Conservation (IIC) y miembro del Grupo Español del IIC; ha sido colaborador de la Agencia Estatal de Investigación para la Joint Programming Initiative "Cultural Heritage and Global Change: a Challenge for Europe", como miembro del Comité Ejecutivo de ésta en representación de España desde 2010 hasta 2017. Actualmente es Coordinador del nodo español de la "European Research Infrastructure on Heritage Science" (E-RIHS). 